\title{
La conquista del mercado editorial peninsular por un novohispano o la renovación de la catequesis urbana en el imperio hispánico (siglo XVIII)
}

\author{
The Conquest of the Peninsular Publishing Market \\ by A Novohispano or the Renewal of Urban Catechesis \\ In the Hispanic Empire (18th Century)
}

\section{Trilce LASKE}

https://orcid.org/0000-0003-0717-8410

Universidad Nacional Autónoma de México (México)

Instituto de Investigaciones Históricas

laske.rosas@gmail.com

\section{Resumen}

Este artículo trata sobre la circulación de ideas dentro del Imperio hispánico en el siglo xviII. Analiza las condiciones de producción en México de Luz de verdades católicas, la obra doctrinal del jesuita novohispano Juan Martínez de la Parra, y luego su exportación exitosa en el corazón histórico del Imperio. Detrás del caso específico del novohispano, el objetivo del texto es interrogar sobre la configuración intelectual del Imperio en favor de una lectura policéntrica.

Palabras clave: Imperio hispánico; historia intelectual; siglo XvıII; circulación de ideas; policentrismo.

\begin{abstract}
This article deals with the circulation of ideas within the Hispanic Empire in the 18th century. It analyzes the production conditions in Mexico of the work of the Jesuit from New Spain Juan Martínez de la Parra, Luz de verdades católicas, and its later diffusion in the historical heart of the Empire. Following the specific case of the novohispano, the objective of the text is to question the intellectual configuration of the Empire in favor of a polycentric reading.
\end{abstract}

Keywords: Hispanic Empire; intellectual history; 18th century; circulation of ideas; polycentrism. 


\section{Introducción}

Durante el año de 1793, la Real Compañía de Impresores y Libreros de Madrid solicitó una licencia de reimpresión al Consejo de Castilla para la obra Luz de verdades católicas. Para los funcionarios reales, se trataba doblemente de una simple formalidad. Primero, la asociación mercantil constituía por entonces un polo altamente legítimo de producción institucional para la literatura religiosa en el Imperio. Estrechamente ligada al monasterio del Escorial y a sus religiosos, poseía el privilegio regio sobre el libro de nuevo rezado. ${ }^{1}$ Segundo, la obra era un clásico del repertorio catequístico en la península. Ya contaba con unas treinta reediciones en España desde el comienzo del siglo, lo que la colocaba entre los libros más reimpresos para el siglo en el Imperio. ${ }^{2}$ En esas condiciones, el Consejo otorgó fácilmente, el 15 de abril de 1793, la licencia solicitada y el nuevo tiraje pudo iniciarse para colocar en el mercado una enésima versión del libro. ${ }^{3}$ Sin embargo, pese a su alto grado de legitimidad y al reabastecimiento continuo en ejemplares, su autor, el jesuita Juan Martínez de la Parra no había pisado nunca la península. Fallecido noventa años antes, en diciembre de 1701, pasó la mayoría de su vida en México. Sobre todo, dirigió Luz de verdades católicas exclusivamente al público novohispano, sin considerar en ningún momento su difusión desmultiplicada más allá de las fronteras del virreinato. ¿Cómo explicar entonces la alta popularidad ultramarina de su obra y su duración entre receptores europeos? A modo de respuesta, este texto pretende mostrar de qué manera el éxito peninsular de la obra novohispana descansó en la configuración misma del Imperio para, al menos, el siglo XVIII.

En efecto, desde hace dos décadas, la disposición interna de la monarquía ha sido revaluada en diferentes niveles en favor, entre otras cosas, de la constatación de un fuerte policentrismo y de un alto grado de integración. Impulsado por acercamientos políticos o económicos, este reequilibraje historiográfico ha dejado de lado, no obstante, por varios motivos, la ver-

${ }^{1}$ Beatriz Lara González, La Real Compañía de Impresores y Libreros de Madrid: siglo XVIII y siglo XIX (Madrid: Universidad Complutense, 2015).

${ }^{2}$ A modo de comparación, Meregalli indica 37 ediciones del Quijote de su primera publicación, en 1605, al final del siglo xviıI en España. Franco Meregalli, La literatura desde el punto de vista del receptor (Amsterdam: Rodopi, 1989), 54.

${ }^{3}$ Archivo Histórico Nacional (en adelante AHN), Consejos, 5559, exp. 84. 
tiente intelectual de la configuración imperial. ${ }^{4} \mathrm{Al}$ contrario, ésta sigue subordinada en gran medida a análisis unipolares, que tienden a aislar a uno solo de sus parámetros: la circulación de este hacia oeste. Por tanto, si bien algunas figuras americanas han suscitado el interés de manera temprana debido al éxito de sus trayectorias inversas o de las de sus obras, tal como el Inca Garcilaso para el siglo XVI o sor Juana para el XVII, la historia intelectual ha privilegiado a nivel imperial el estudio de fenómenos de exportación del corazón histórico de la monarquía hacia sus territorios transatlánticos, en relación por ejemplo, hoy en día, con los conceptos de transferencia y reapropiación..$^{5}$ Ahora bien, sin negar su importancia, esta circulación no es más que una variable entre otras para el siglo xviII.

El objetivo de este artículo es, por lo tanto, triple. En primer lugar, señala el carácter intrínsecamente local de la obra del jesuita novohispano. Producida en y para México, Luz de verdades católicas fue el producto tanto de un contexto institucional como cultural propio de la capital del virreinato americano. En segundo lugar, este texto se dedica a los fundamentos de su exportación exitosa hacia el corazón histórico de la monarquía y a los motivos de su popularidad en la península. Lejos de constituir una excepción, el éxito transatlántico de la obra de Martínez de la Parra dependió de la densidad de los circuitos en el Imperio y de la coherencia de la identidad imperial. En última instancia, se trata aquí de demostrar, con Luz de verdades católicas, la amplitud de las difusiones intelectuales en el siglo XVIII, no desde los territorios europeos de la monarquía hacia sus tierras americanas, sino a la inversa: de oeste a este.

El nacimiento de una obra: una fórmula capitalina

Impresa por primera vez en México, Luz de verdades católicas fue publicada inicialmente en tres tomos sucesivos en 1691, 1692 y 1696. Su éxito fue

${ }^{4}$ Véase en particular: Pedro Cardim y Gaetano Sabatini, eds., Polycentric Monarchies. How did Early Modern Spain and Portugal Achieve and Maintain a Global Hegemony? (Sussex: Academic Press, 2014). Sobre el cambio historiográfico y sus causas: María Fernanda Justiniano, "América: de colonia a reino y de periferia a centro", Nuevo Mundo, Mundos Nuevos (2016), doi:10.4000/nuevomundo.69742.

${ }^{5}$ Por ejemplo: Inmaculada Rodríguez Moya, ed., Iberoamérica en perspectiva artística transferencias culturales y devocionales (Castelló: Universitat Jaume I, 2016); Macarena Cordero, "Reproducción y traducción de la cultura judicial hispana en el imaginario indígena", Estudios de Historia Novohispana, n. 57 (2017): 8-26, https://doi.org/10.1016/j. ehn.2017.06.002. 
inmediato entre el público capitalino y, para cada volumen, los ejemplares a la venta se agotaron rápidamente. Su autor, Juan Martínez de la Parra, era un jesuita de unos cuarenta años, originario de la diócesis de Puebla, que había cursado los estudios clásicos de su orden. ${ }^{6}$ Luego del noviciado y de una breve estancia en Ciudad Real y Guatemala a finales de los años de 1670, el jesuita residió desde los años de 1680 en la Casa Profesa de México, donde redactó su obra para sus círculos de feligreses. Por dos razones principales, ésta fue un producto intrínsecamente capitalino. Por una parte, surgió de circunstancias institucionales accidentales, específicas de la provincia jesuita de la Nueva España. Por otra, respondió a expectativas tanto nacientes como propias del público de la capital.

En efecto, la Casa Profesa atravesó, por los años de 1690, una grave crisis institucional, la cual tuvo repercusiones esenciales en la elaboración de Luz de verdades católicas. Desde su fundación, unos cien años antes, el establecimiento constituía el bastión de la elocuencia sagrada ignaciana en el virreinato y reunía a los mejores predicadores de la provincia jesuita novohispana. Oradores tan famosos como el portugués Bartolomé Castaño o el queretano Juan de Robles ocuparon su púlpito. Hacia 1685, sus predicadores estrellas eran los jóvenes jesuitas Pedro de Avendaño, Juan Martínez de la Parra o Gaspar de los Reyes. ${ }^{7}$ Gracias a un estilo brillante, los tres treintañeros conglomeraban con éxito a los fieles en cada una de sus comparecencias. Sin embargo, en el transcurso del año de 1688, Avendaño resultó comprometido en un asunto de faldas, que provocó finalmente su expulsión de la Compañía de Jesús durante el año de $1690 .{ }^{8}$ De hecho, los actos cometidos por el jesuita eran graves. Así como él mismo lo reconoció ante la Inquisición el 10 de diciembre de 1688, había mantenido relaciones con feligresas, algunas casadas. ${ }^{9}$ En la provincia ignaciana, no obstante,

${ }^{6}$ Juan Martínez de la Parra nació en 1653 en Huejotzingo, cerca de Puebla. Para su trayectoria: Manuel Pérez, Los cuentos del predicador: historias y ficciones para la reforma de costumbres en la Nueva España (Madrid: Iberoamericana, 2011); Trilce Laske, "Un eclesiástico con dimensión imperial en México: Juan Martínez de la Parra y la consagración intelectual (1680-1701)", Historias, n. 99 (2018): 33-50.

7 Tanto Avendaño como Reyes nacieron en la Nueva España en 1655, el primero en Cuautla de las Amilpas y el segundo en Villa de Carrión. Archivum Romanum Societatis Iesu (en adelante ARsi), Catálogos trienales de la Provincia de la Nueva España.

8 "Lunes 15, expelieron de la Compañía al Padre Pedro de Avendaño, grande predicador", Antonio Robles, Diario de sucesos notables (México: Porrúa, 1972), v. II, 212.

9 Archivo General de la Nación (en adelante AGN), Instituciones Coloniales, Inquisición, v. 520, exp. 151. 
otros miembros ya habían sido implicados en asuntos similares sin por tanto exponerse a una expulsión, por lo cual es probable que la severidad del veredicto en contra de Pedro de Avendaño haya tenido que ver con un ajuste de cuentas interno. ${ }^{10}$

Notoria en la ciudad por el mes de octubre de 1690, la salida de Avendaño sumió a la provincia jesuita en la crisis. Figura emblemática de la predicación ignaciana desde hacía unos años, la expulsión de Avendaño desacreditaba a la Compañía. Sobre todo, atentaba contra el decoro y la respetabilidad de la Casa Profesa en torno a rumores de indisciplina en la capital. Para restaurar la reputación del establecimiento, los superiores jesuitas optaron entonces por una profunda y visible reforma tanto humana (gestión del personal) como política (línea religiosa). Por una parte, el equipo de La Profesa fue reorganizado. Para su dirección, el general Tirso González designó desde Roma al teólogo Alonso de Ramos. ${ }^{11}$ Se trataba pues de una señal fuerte. En efecto, Ramos no formaba parte del grupo de dignatarios escogidos normalmente para dirigir la Casa Profesa. El gobierno del establecimiento representaba uno de los últimos escalones del cursus honorum ignaciano antes del provincialato, por lo cual era reservado a individuos experimentados. Ahora bien, Ramos nunca había asumido hasta la fecha cargos de mando, fuera de tres años en el rectorado del colegio de Mérida, diez años antes, de 1677 a $1680 .{ }^{12}$ Además, el nuevo prepósito era una personalidad casi desconocida en la capital por haberse desempeñado

${ }^{10}$ Avendaño era muy cercano a un importante dignitario jesuita, Bernardo Pardo, que acababa de fallecer en junio de 1686. Luego de un periodo de luchas intestinas en la década de 1670, Pardo había alcanzado el provincialato en 1680 y se aprovechó de su nombramiento para quitar y distribuir puestos, lo cual fortaleció las enemistades internas. Su muerte, a los 67 años de edad, dejó sin duda muy expuesto a su allegado Avendaño. Para la muerte de Pardo, véase: Robles, Diario, v. II, 121. Para las luchas internas en la provincia jesuita: ARSI, Mex., 3, f. 118v, 119v y 124v. Para la actuación de Pardo como provincial: ARSI, Mex., 3, f. 146r-150v. La cercanía de Avendaño con Pardo aparece en el apadrinamiento, por Avendaño, de su sobrino Diego Gabriel Pardo de Lagos, el 30 de junio de 1688 en la catedral capitalina.

${ }^{11}$ Nacido en 1655, Ramos era originario de Castilla. Llegó a la Nueva España en 1658. Más tarde, caería en el alcoholismo. Archivo General de Indias (en adelante AGI), Contratación, 5431, n. 5, r. 78; José Gutiérrez Casilla, Diccionario bio-bibliográfico de la Compañía de Jesús en México (México: Jus, 1961), v. Xvi, 412-413.

12 ARSI, Catálogos trienales. De la Maza, seguido por Rice, atribuye a Ramos el rectorado del Colegio del Espíritu Santo de Puebla durante la década de 1680. Sin embargo, ese cargo no aparece ni en los catálogos trienales ni en las cartas romanas de asignación de los cargos. Ramos ocuparía el rectorado poblano solamente después de su mandato en la Profesa, a partir de 1693. 
lejos de ella. Para las autoridades centrales de la Compañía, el nombramiento de un miembro poco conocido y alejado de los más altos círculos del poder constituía precisamente una prueba manifiesta de toma de control. En paralelo, el grupo de oradores sacros que operaba con Avendaño desde 1685 en La Profesa fue disuelto. Además de la expulsión del joven jesuita, su correligionario Martínez de la Parra fue removido de la predicación en el establecimiento, mientras que Gaspar de los Reyes fue trasladado a uno de los colegios de la Compañía en Puebla. ${ }^{13}$

Por otra parte, las autoridades jesuitas modificaron, bajo la nueva dirección de Ramos, la política de la Casa Profesa a favor de una mayor ejemplaridad apostólica. Si bien la política del establecimiento había sido dominada hasta entonces por el esfuerzo oratorio, se desplazó de manera provisoria hacia la acción catequística con la fundación de una Congregación de la Doctrina de Cristo. ${ }^{14}$ Aunque representara un ministerio menor en comparación con la predicación, la enseñanza del catecismo ofrecía por lo general el beneficio de una alta legitimidad religiosa por su valor evangélico. Sobre todo, como tradicional polo modelo de catequización dentro del espacio católico, la promovían en particular en la capital las autoridades eclesiásticas. ${ }^{15} \mathrm{Si}$ bien suscitó reticencias en otros territorios tanto entre el clero como entre los fieles, la enseñanza sistemática de la doctrina había sido asumida de manera precoz y duradera por parte del personal arquidiocesano. ${ }^{16}$ Por los años de 1690, la fomentaba activamente el arzobispo Aguiar y Seixas. ${ }^{17}$ En el contexto de la expulsión de Avendaño, la inflexión

${ }^{13}$ ARSI, Catálogos trienales.

${ }^{14}$ Según el catálogo trienal de 1693. ARsi, Catálogos trienales.

15 Mayer señala la "fuerte tridentinización de las iglesias americanas": Alicia Mayer, "La Reforma católica en Nueva España. Confesión, disciplina, valores sociales y religiosidad en el México virreinal", en La Iglesia en la Nueva España. Problemas y perspectivas de investigación, coord. de María del Pilar Martínez López-Cano (México: Universidad Nacional Autónoma de México, 2010), 16.

${ }^{16}$ En algunos espacios europeos, la aplicación de las directivas tridentinas fue dificultada por las reticencias del clero o de la feligresía. En México el imperativo del adoctrinamiento fue consignado en los cuatro puntos iniciales del Primer Concilio Mexicano de 1555. María del Pilar Martínez López-Cano, Concilios provinciales mexicanos (México: Universidad Nacional Autónoma de México, 2004). Por su parte, el primer arzobispo, Juan de Zumárraga, redactó y promocionó varios catecismos. Sus sucesores prolongaron luego su acción, respaldados además por los siempre más numerosos contingentes de curas procedentes de la Universidad.

17 Véase José de Lezamis, Breve relación de la vida, y muerte del Ill. y Rmo. Señor Doctor D. F. de Aguiar, y Seyjas (México: Imp. Benavides, 1699), [f. 8v; 28v]. 
de la política de La Profesa presentaba, por lo tanto, un doble interés para los superiores jesuitas. Por un lado, permitía exponer públicamente la remoralización del establecimiento. Por otro, manifestaba a los ojos de las autoridades eclesiales del arzobispado la sujeción de La Profesa a su calendario gubernamental luego de la publicidad negativa creada por la exclusión de unos de sus predicadores predilectos.

Para dirigir este nuevo esfuerzo doctrinario, los superiores jesuitas se inclinaron, hacia el mes de marzo de 1690, por el último representante en La Profesa del grupo de oradores sacros de los últimos años: Juan Martínez de la Parra. ${ }^{18}$ Otros miembros del establecimiento, como los misioneros Juan del Castillo o José Ximénez, habrían sido no obstante más adecuados al ministerio catequístico. En efecto, éste correspondía a la explicación, con un lenguaje simplificado, de nociones básicas del dogma, como el Credo o el decálogo. Al contrario, Martínez de la Parra se había suscrito hasta entonces a un arte oratorio particularmente elaborado, compuesto por conceptos predicables y elegantes figuras de estilo. En el contexto de la expulsión de Avendaño, la relegación del orador predilecto de la predicación a la doctrina funcionó, sin duda, como una prueba más de enmienda pública de parte de las autoridades jesuitas. De hecho, si bien dependió de cálculos políticos pensados en un contexto de crisis, el desplazamiento de Martínez de la Parra resultó particularmente exitoso para la Compañía. Constituyó el primer detonante indiscutible de la Luz de verdades católicas. En cuanto doctrinero inesperado, el jesuita poblano transformó la catequesis capitalina a través de series de pláticas, las cuales iban a formar la materia prima de su obra.

Por entonces, el dispositivo de catequización de los feligreses en México se organizaba en dos principales vertientes complementarias. Por un lado, se trataba de una enseñanza rudimentaria, llevada en las iglesias parroquiales o en las escuelas de primeras letras, con base en textos elementales tal como el catecismo de Gerónimo de Ripalda, que constituía el manual de referencia para los doctrineros desde los años de 1620. ${ }^{19}$ Estructurada en cuestiones y respuestas breves, la obra de Ripalda se fundaba sobre un acer-

${ }_{18}$ Para la fecha, nos basamos en la primera plática de Martínez de la Parra, el 7 de abril de 1690.

${ }^{19}$ Para esta vertiente de la catequesis, también se practicaba la enseñanza itinerante, llevada en particular por los jesuitas. Para las escuelas de primeras letras: Pilar Gonzalbo, Historia de la educación en la época colonial: la educación de los criollos (México: Fondo de Cultura Económica, 1990), 25-39, 319-327. Sobre la importancia del catecismo de Ripalda 
camiento simple y deductivo del dogma: conocer y luego aplicar. Por otro lado, la enseñanza catequística se realizaba también desde los púlpitos capitalinos a través de pláticas que se detenían en puntos de doctrina específicos. ${ }^{20}$ Después de la misa de los domingos, el propio arzobispo Aguiar y Seijas se suscribía por entonces al ejercicio en la catedral. ${ }^{21}$ Por su forma discursiva, esta vertiente de la catequesis tendía a ser un poco más elaborada que la otra. Sin embargo, se formulaba también en un lenguaje voluntariamente simple, con "palabras sencillas" y en un "estilo humilde". ${ }^{22}$ Dado su relevancia, había conocido durante las últimas décadas dos innovaciones significativas. En primer lugar, la forma del comentario fue incorporado a su metodología. Para construir sus discursos, los doctrineros podían basarse en citaciones de catecismos elementales como el de Ripalda, las cuales constituían el "punto de partida estratégico" de sus pláticas. ${ }^{23}$ En segundo lugar, las narraciones breves se fueron imponiendo como elementos pedagógicos ineludibles en la trama de las pláticas. ${ }^{24}$ Popularizado por el jesuita Juan Eusebio Nieremberg con su Práctica del catecismo publicado en 1640, el proceder favorecía el interés y la memorización de los auditorios.

Destinado por sus superiores a esta segunda vertiente de la catequesis, Juan Martínez de la Parra asumió en parte las normas en vigor para el género. Basándose en el catecismo de Ripalda, se dedicó cada jueves a explicar en el púlpito de La Profesa puntos clave de doctrina durante pláticas de media hora, las cuales concluía sistemáticamente por un relato. Desde el inicio, el poblano introdujo no obstante también una alta dosis

en la Nueva España: Alicia Mayer, Lutero en el paraíso. La Nueva España en el espejo del reformador alemán (México: Fondo de Cultura Económica, 2008), 75-76.

${ }^{20}$ Formó parte de las obligaciones de los curas señaladas desde el primer concilio de México: “Otrosí, mandamos a todos los curas que agora son o serán de aquí adelante, que en todos los domingos de el adviento y desde el domingo de la septuagésima hasta la dominica in pasione inclusive, lean y declaren al pueblo las cosas contenidas en la dicha tabla en la misa mayor después de el ofertorio, y lo que de ello no se pudiere leer en un domingo se lea en otro, o en la primera fiesta que ocurriere”. Martínez López-Cano, Concilios, 4.

21 "Muchas veces hazia alguna plática de Doctrina, de las que tenemos los Domingos, quando no ay sermón, después de Missa mayor en la Cathedral.” Lezamis, Breve relación, $[28 \mathrm{v}]$.

${ }^{22}$ Félix Herrero Salgado, La oratoria sagrada en los siglos XVI y XVII (Madrid: Fundación Universitaria Española, 1998), v. III, 392-393; Pérez, Los cuentos, 45.

${ }^{23}$ Luis Resines, La catequesis en España. Historia y textos (Madrid: Biblioteca de Autores Cristianos, 1997), 406. Por ejemplo, las obras catequísticas de Juan del Campo (1676), de José Ortiz Cantero (1705) o de José Martín de la Sierra (1718) se constituyen con base en el comentario del catecismo de Ripalda.

${ }^{24}$ Resines, La catequesis, 337. 
de novedad. Relegado por una crisis accidental a la catequesis, trabajó en parte su enseñanza doctrinal a partir de su excelencia oratoria previa. Combinando predicación y doctrina, llegó a producir una catequesis híbrida. En cuanto erudito, Martínez de la Parra no ignoraba las convenciones en torno al lenguaje sencillo de la doctrina. Tal como lo reconoció en 1691: "Bien sé, pues, que esto de explicar la Doctrina Christiana, lo dieron en tomar por una narración llana, sencilla y humilde, y sin más cuidado, ni artificio, que dezir con claridad". ${ }^{25}$ Pese a ello, incorporó a sus pláticas técnicas oratorias más complejas, procedentes de la elocuencia sagrada. En particular, importó dos elementos específicos de la predicación: el tono deliberativo y el cuidado estilístico. Por una parte, incorporó la implicación emocional del orador. ${ }^{26}$ Por otra, el nuevo doctrinero integró la necesidad estética. ${ }^{27}$ De ese modo, elaboró una doctrina elegante y compleja, que rompía con el modelo rudimentario de la catequesis vigente. Al acercarse al sermón, elevaba pues el nivel general del discurso doctrinario. ${ }^{28}$ Para Martínez de la Parra, esta fórmula innovadora prolongaba su especialización anterior y sus prácticas de trabajo. De manera inesperada no obstante, confluyó con nuevas expectativas de renovación devocional que se estaban gestando en México.

Desde sus comienzos, el jueves 7 de abril de 1690, la doctrina de Juan Martínez de la Parra tuvo pues gran éxito en la capital. En un primer momento, el jesuita atrajo sin duda a los fieles con base en su condición reciente de orador famoso. Pero rápidamente, su auditorio aumentó para

${ }^{25}$ Martínez de la Parra explicitó y explicó luego sus dudas y elecciones en el primer tomo de Luz de verdades católicas. Juan Martínez de la Parra, Luz de verdades católicas (Barcelona: Imp. Jolis, 1701), [f. 6r]. Por razones prácticas, usaremos principalmente esta edición para las diferentes citas, salvo menciones explícitas.

26 "Porque el enseñar solo [...], como para en el entendimiento, sin procurar excitar los afectos, se dize con frialdad, y con frialdad se oye, y serviría de poco dexar en el entendimiento las noticias, sin excitar juntamente la voluntad a lograrlas, debiendo ser nuestra Fe practica y executiva para las buenas obras." Martínez de la Parra, Luz de verdades, 1701, [f. $7 r]$.

27 "Procuro dezirlo todo, de modo, que los unos me entiendan, y no por esso descuydo de atender sin afectación a la pureza de las voces, que los otros gustan. Introduzgo tal vez alguna floresica, que coja el entendido", Martínez de la Parra, Luz de verdades, 1701, [f. 5v].

${ }^{28}$ Según un comentarista: "no hay en la oratoria Sagrada condición que falte a estas pláticas: por que las materias son gravissimas, las voces claras, el acento sonoroso, la energía ardiente, el pensar sublime, el adornar lucido, con que a un tiempo enseña, deleyta y aficiona”. Juan Martínez de la Parra, Luz de verdades católicas (Sevilla: Imp. J. Fco. Blas, 1699), v. III, [f. 4r]. Para un análisis más detallado: Laske, "Un eclesiástico". 
rebasar los límites de la curiosidad en favor de un entusiasmo colectivo. El 12 de marzo de 1691, el jesuita Fernando de Valtierra comentó de qué manera "los que en [México] viven, pienso que viven de oír a este Predicador [Martínez de la Parra]". ${ }^{29}$ Un año más tarde, el 15 de marzo de 1692, el mismo Martínez de la Parra señaló: "Sera bendición de Dios ver qué? Lo que todos vemos, como acuden a la explicación de la Doctrina todos a porfía, a tropas, como crecen, como se aumentan las doctrinas, como se llena la Iglesia. [...] Sera bendición de Dios si el crecer de la Doctrina fuere, más que en el concurso de oyentes, en el numero de aprovechados". ${ }^{30}$

Sorprendente para la doctrina, este éxito del poblano entre el público de México descansó sobre expectativas de renovación que estaban surgiendo en la ciudad y para las cuales sus pláticas se presentaron como una primera respuesta tanto inesperada como apropiada. En efecto, mutaciones importantes de orden religioso estaban incubando en la capital virreinal desde hacía ya algún tiempo. Por una parte, el público capitalino se veía progresivamente afectado por un fenómeno de interiorización de las devociones. ${ }^{31}$ Bajo el impulso de un sector seglar con fuertes valores mercantiles e individualistas, las formas de la devoción en México tendían a romper desde hacía varios años con las expresiones barrocas en favor de manifestaciones más discretas y sobre todo personales. Por otra parte, proposiciones inéditas de severidad devocional, en particular en torno al antiprobabilismo, estaban extendiéndose en México. Apoyados por la acción del papa Inocencio XI (1676-1689) entre otros, una parte del clero capitalino había llevado con éxito, desde los años de 1680, una campaña dinámica de promoción del rigorismo, que impulsaba una mayor implicación individual de los fieles en su devoción. ${ }^{32}$ De manera paulatina, estas transformaciones socavaban la cultura teológica postridentina vigente en México a favor de una nueva forma de espiritualidad, más individualizada. A nivel catequís-

${ }^{29}$ Martínez de la Parra, Luz de verdades, 1699, v. I, [f. 6v].

${ }^{30}$ Martínez de la Parra, Luz de verdades, 1701, 258.

${ }^{31}$ Antonio Rubial, "Un nuevo laico ¿un nuevo Dios? El nacimiento de una moral y un devocionalismo 'burgueses' en Nueva España entre finales del siglo XVII y principios del XVIII", Estudios de Historia Novohispana, n. 56 (2017): 1-25, doi.org/10.1016/j.ehn.2017.01.005.

${ }^{32}$ Francisco Sánchez, Examen de las indulgencias que legitimamente gozan las Religiones, $y$ Cofradias (Madrid: Imp. Garcia Infancon, 1680); Tomás Velasco, Breviloquio moral practico, en que se contienen las sesenta y cinco proposiciones prohibidas por N. SS. P. Innocencio XI (México: Imp. Viuda Calderón, 1681); Matias Rodriguez, Explicación de las sesenta y cinco proposiciones prohibidas por la santidad de N. M. S. P. Innocencio XI (Puebla: Imp. Fernández de León, 1684). Sobre el papel del rigorismo en la renovación de la catequesis: Resines, La catequesis, 379-381. 
tico en particular, ambas empujaban "a adquirir [...] una mejor y más completa formación religiosa" y a renovar los instrumentos de la doctrina. ${ }^{33}$

En ese contexto, la doctrina innovadora de Martínez de la Parra se presentó precisamente como una solución oportuna. Primero, el jesuita proponía un discurso doctrinario cuyo grado de complejidad coincidía con las nuevas expectativas devocionales de sus auditores. Segundo, el cuidado estético dado a su discurso contribuyó también a atraer fieles tan aficionados y exigentes en materia oratoria como los de la capital. Frente a la adhesión tan rápida como inesperada del público de México, las autoridades jesuitas se alegraron. Todavía marcadas por el escándalo de la expulsión reciente de su predicador Pedro de Avendaño, se aprovecharon del éxito sorprendente de su nueva política catequística para otra vez manifestar la remoralización de la Casa Profesa. A partir del mes de diciembre de 1690, apenas nueve meses después de los inicios de Martínez de la Parra a la doctrina, el nuevo prepósito del establecimiento, Alonso de Ramos, emprendió el proceso de publicación de la catequesis sofisticada de su subordinado. ${ }^{34}$ Titulada Luz de verdades católicas, la obra salió probablemente por el mes de agosto de 1691 en las prensas del impresor Diego Fernández de León. ${ }^{35}$ No sólo fue dedicada al fiscal inquisitorial que había archivado el expediente de Avendaño y evitado preocupaciones a La Profesa, sino también la inauguró una larga introducción que señalaba el esfuerzo constante de la Compañía para la catequización de los feligreses. A pocos meses del escándalo, las autoridades provinciales ignacianas terminaban pues de saldar cuentas mientras que reafirmaban públicamente la integridad moral de La Profesa y la importancia de su acción evangélica.

Así como su versión oral, la publicación de la doctrina del poblano tuvo muy buena acogida en México, tanto entre los fieles como entre los eclesiásticos. De hecho, esta primera impresión de Luz de verdades católicas se agotó rápidamente. ${ }^{36}$ Sobre todo, su éxito llevó a la publicación de toda la

${ }^{33}$ Resines, La catequesis, 373.

${ }^{34}$ La licencia del Provincial se dio el 20 de diciembre de 1690. Martínez de la Parra, Luz de verdades, 1701, [f. 12v]. El papel activo de Ramos en la publicación aparece en la misma portada de la obra.

${ }^{35}$ Fernández de León trabajaba en Puebla, pero instaló para un par de años unas prensas en la Casa Profesa. José Toribio Medina, La imprenta en la Puebla de los Ángeles (Santiago de Chile: Imp. Cervantes, 1908), xxviII.

${ }^{36}$ Las versiones de esa edición prínceps son sumamente escasas. La única que hemos podido localizar en los archivos corresponde a la de la Biblioteca Lafragua de Puebla. La Biblioteca Nacional de México, la Biblioteca del Museo de Antropología, el Condumex, 
obra catequística del jesuita (véase el cuadro 1). Un año más tarde, en 1692, las autoridades ignacianas publicaron en efecto un segundo tomo de las pláticas de Martínez de la Parra. Además de dedicarse esta vez a una alta figura de la aristocracia novohispana, el mariscal de Castilla Carlos de Luna y Arellano, la obra recibió el patrocinio público del poderoso arzobispo capitalino, Francisco de Aguiar y Seixas, el cual sólo podía felicitarse del entusiasmo en su jurisdicción para una obra doctrinaria. ${ }^{37}$ Luego, un tercer tomo de Luz de verdades católicas salió a finales de 1696, costeado por un importante librero de la ciudad: José Guillena Carrascoso. ${ }^{38}$

Del mismo modo que el primer volumen, el segundo y el tercer tomos se vendieron muy bien, lo cual empujó a los jesuitas novohispanos a considerar, desde 1698, una reedición abundante de la obra de su doctrinario para abastecer a sus fieles. ${ }^{39}$ Para grandes tiradas, las imprentas capitalinas eran sin embargo poco ventajosas dado el alto costo del papel en el virreinato. ${ }^{40}$ Las autoridades ignacianas se volcaron entonces hacia la oferta peninsular, menos costosa. El proceder era por entonces común entre la intelectualidad novohispana. Dos personalidades tales como el dominico Francisco Sánchez y el jesuita Miguel de Godínez habían publicado, por ejemplo, en 1680 y 1682 dos obras en Madrid y Sevilla para traerlas de vuelta luego a la Nueva España. ${ }^{41}$

Por dos razones principales, las autoridades jesuitas se inclinaron por las prensas del impresor sevillano Juan Francisco de Blas. Primero, su residencia

la Biblioteca Nacional de España y la Biblioteca Nacional de Chile no poseen en sus colecciones un solo ejemplar de esa primera edición.

${ }^{37} \mathrm{El}$ arzobispo concedió 40 días de indulgencia a los lectores de este segundo tomo, lo cual se señaló en la portada misma de la obra.

${ }^{38}$ Según el pie de imprenta: "Joseph Guillena Carrascoso, Impressor y Mercader de libros, a cuya costa se imprime en México". Este tomo también obtuvo el apoyo del prelado capitalino con otros 40 días de indulgencia para los lectores.

${ }^{39}$ De hecho, de esas dos ediciones prínceps, sólo hemos podido localizar el tercer tomo en la Biblioteca Nacional de Chile.

${ }^{40}$ La penuria de papel fue un problema recurrente. En 1677, Robles escribió por ejemplo que: "Este año se ha encarecido el papel [...]; se han desbaratado muchos libros para vender por papel escrito; se han dejado de imprimir muchas obras y han estado paradas las imprentas y lo han padecido los oficiales", Robles, Diario, v. I, 229. Sobre la actividad de los impresores en México en el siglo xVII, véase Ariel Morán Reyes, "No hay término ni fin en hacer ni multiplicar los libros. Las casas de impresores y la diversificación de la cultura libresca durante el siglo Xviı en la capital novohispana”, Revista Complutense de Historia de América, n. 45 (2019), 159-187, doi.org/10.5209/rcha.64691.

${ }^{41}$ Sánchez, Examen de las indulgencias; Miguel Godínez, Práctica de la theologia mystica (Sevilla: Imp. Juan Vejarano, 1682). 
en Sevilla limitaba los costos de transportes a la travesía atlántica, a diferencia de otras prensas peninsulares. Situada en el punto de partida de la flota, bastaba luego de la impresión sólo con cargar los libros en los barcos. Segundo, Blas era un colaborador de confianza de los jesuitas americanos. En 1673, ya había publicado una obra del jesuita novohispano Francisco de Florencia. ${ }^{42}$ En 1701, imprimiría las clases completas de filosofía del jesuita limeño José de Aguilar. ${ }^{43}$ En 1699, reeditó entonces los tres tomos de Luz de verdades católicas. ${ }^{44}$ Los nuevos ejemplares llegaron probablemente a México durante el año de 1700 para alimentar la demanda local. ${ }^{45}$ Sobre todo, hicieron que la obra pasara de una difusión limitada a una intensiva en el virreinato. A diez años del escándalo que sacudió la Casa Profesa, se trató de una verdadera rehabilitación para el establecimiento.

Relegado accidentalmente de la alta predicación a la doctrina para conducir en 1690 la campaña de remoralización de La Profesa, Juan Martínez de la Parra trabajó la doctrina con los instrumentos de la elocuencia sagrada. De ese modo, produjo una catequesis híbrida, que mezclaba elementos de doctrina con un refinamiento y una complejidad del discurso procedentes de la alta predicación. Inesperada, esta innovación confluyó precisamente con las expectativas y gustos de una espiritualidad más severa e individualista que se estaba extendiendo en la capital virreinal desde hacía varios años. La doctrina del poblano propuso pues en un lenguaje atractivo una profundización devocional a los fieles. En este sentido, Luz de verdades católicas funcionó como una actualización de la enseñanza doctrinaria. Fue esta renovación del catecismo, llevada a cabo en México con base en parámetros propios, la que iba a suscitar rápidamente el interés fuera de las fronteras del virreinato y, entre otros, en la península.

${ }^{42}$ Fue durante la estancia de Florencia en Europa, como procurador provincial. Francisco Florencia, Exemplar vida y gloriosa muerte por Christo del fervoroso P. Luis de Medina (Sevilla: Imp. Juan Francisco de Blas, 1673).

${ }^{43}$ José de Aguilar, Cursus philosophicus dictatus Limae (Sevilla: Ioannis Francisci de Blas, 1701).

${ }^{44}$ Se reprodujeron todos los paratextos legales y las licencias del virrey y del ordinario para la impresión en la Nueva España. Sólo se unificaron las diferentes dedicatorias, dadas en contextos distintos, en beneficio de un santo jesuita americano por excelencia, Francisco Xavier, apóstol de las Indias.

${ }^{45}$ La edición sevillana llegó por ejemplo a las bibliotecas de los conventos de San Diego de México y de Santa Bárbara de Puebla según los exlibris de los ejemplares conservados en la Biblioteca de Lima y la Biblioteca Nacional de México. 
Cuadro 1

EDICIONES DESTINADAS AL MERCADO NOVOHISPANO

(FUERTE REABASTECIMIENTO)

\begin{tabular}{|c|c|c|c|}
\hline Año & Título & Impresor & Lugar \\
\hline 1691 & $\begin{array}{l}\text { Luz de verdades católicas y explica- } \\
\text { ción de la doctrina }\end{array}$ & Diego Fernández de León & México \\
\hline 1692 & $\begin{array}{l}\text { Luz de verdades católicas. Segunda } \\
\text { parte de la explicación }\end{array}$ & Diego Fernández de León & México \\
\hline 1696 & $\begin{array}{l}\text { Luz de verdades católicas }[. . .] \text {. Ter- } \\
\text { cera parte }\end{array}$ & José Guillena Carrascoso & México \\
\hline 1699 & $\begin{array}{l}\text { Luz de verdades católicas, primera } \\
\text { parte de la explicación }\end{array}$ & Juan Francisco de Blas & Sevilla \\
\hline 1699 & $\begin{array}{l}\text { Luz de verdades católicas, segunda } \\
\text { parte de la explicación }\end{array}$ & Juan Francisco de Blas & Sevilla \\
\hline 1699 & $\begin{array}{l}\text { Luz de verdades católicas, tercera } \\
\text { parte de la explicación }\end{array}$ & Juan Francisco de Blas & Sevilla \\
\hline
\end{tabular}

El éxito peninsular: alta conectividad y cohesión imperial

Para comienzos del año de 1698, cuando la reedición sevillana de 1699 aún se estaba planificando, la obra del poblano ya había rebasado las fronteras regionales. El 28 de enero, el exrector de la Universidad de México, el doctor Agustín Cabañas, señaló que "en este, y en otros dilatados reynos, reparte este Maestro Predicador sus doctrinas". ${ }^{46}$ Unos días más tarde, el 2 de febrero, el mercedario Alcocer y Sariñana afirmó a su vez: "aunque parece se estrecha su doctrina en aquellas sagradas paredes de la Casa Professa de esta Corte, llega su lluvia como nube hasta las más remotas partes de nuestro orizonte". ${ }^{47}$ Esta primera circulación de Luz de verdades católicas fuera de la Nueva España se dio tal vez en espacios cercanos como las Filipinas o el Perú. ${ }^{48}$ Limitada por el todavía escaso número de ejemplares, fue

${ }^{46}$ Juan Martínez de la Parra, La nada y todas las cosas, unidas en la santidad admirable de [...] S. Francisco de Assis (México: Imp. Benavides, 1698), [f. 5r].

${ }^{47}$ Juan Martínez de la Parra, Memoria agradecida a la dedicación del sumptuoso retablo (México: Imp. Benavides, 1698), [f. 6v]. También: "pues ya que no personalmente predique en todo lugar como nube predicadora y luzida no se esconde a sus escritos lo más remoto aun del orbe". Martínez de la Parra, Memoria, [f. 6v].

${ }^{48}$ En 1700, el impresor barcelonés Jolis señaló: "Mereció este Libro los aplausos de la India”. Martínez de la Parra, Luz de verdades, 1701, [f. 1v]. 
probablemente impulsada por lectores entusiastas, seglares o eclesiásticos. Luego, algunos meses después, en 1700, a pesar de prepararse la guerra de Sucesión, la obra fue recuperada y exportada en la península a través de un canal muy activo pero ajeno al ideal evangélico: los circuitos del mercado del libro.

Adelantándose a una implicación jesuita para promover una obra ignaciana, los introductores de Luz de verdades católicas en España fueron en efecto los circuitos mercantiles imperiales con base en el cálculo prosaico de beneficios económicos. Posiblemente por el mes de 1699, la obra del poblano empezó a interesar a un grupo de impresores barceloneses en relación comercial con las Indias, entre los cuales se encontraba José Llopis. Desde los años de 1680, el catalán dirigía parte de su negocio hacia el mercado americano. Al lado de libros en catalán o sobre la política del principado, se dedicaba a publicar obras clásicas del catálogo de la literatura religiosa que destinaba en parte a satisfacer la demanda en el virreinato novohispano, cuyas prensas eran fáciles de rivalizar por el alto precio del papel (véase el cuadro 2). De manera puntual, el impresor catalán imprimía también autores o textos relacionados con la Nueva España, así como la Historia de la Conquista de México de Solís en 1691. Sobre todo, el barcelonés no dudaba en utilizar sus prensas en sentido inverso con base en una lógica de ganancia.

Entre los años 1690 y 1692, los lazos comerciales de José Llopis con la Nueva España le permitieron pues conseguir dos libros de villancicos de sor Juana, aún inéditos en la península. Llopis los obtuvo probablemente por medio de su impresor novohispano, Diego Fernández de León, con quien debía mantener negocios. ${ }^{49}$ Desde 1689 , la obra de la monja se vendía muy bien en España. El empresario aprovechó entonces tener la primicia de ambos libros para comercializar en el mercado peninsular, en 1691 y 1693, versiones no-autorizadas y aumentadas de la obra de la poetisa. Fue probablemente por este mismo canal que, por 1699, Llopis obtuvo ejemplares de Luz de verdades católicas. Así como para los villancicos de sor Juana, Fernández de León había sido el impresor de los tomos 1 y 2 de la doctrina del poblano. En vista de su considerable éxito en México, le era fácil al impresor novohis-

${ }^{49}$ Es la hipótesis manejada por Jorge Gutiérrez Reyna, "El texto del Primero sueño. Transmisión, editores, retos de la edición crítica”, (An)ecdótica, n. 3 (2019): 71-92. Sobre las ediciones de las obras de sor Juana por el catalán, nos basamos en los trabajos de: David Galicia Lechuga y Jorge Gutiérrez Reyna, “Un impresor seducido por sor Juana: los textos de las sueltas novohispanas publicados por José Llopis en poemas (1691)”, Calíope, n. 23 (2018): 217-233: doi.org/10.5325/caliope.23.2.0217; Gutiérrez Reina, "El texto". 


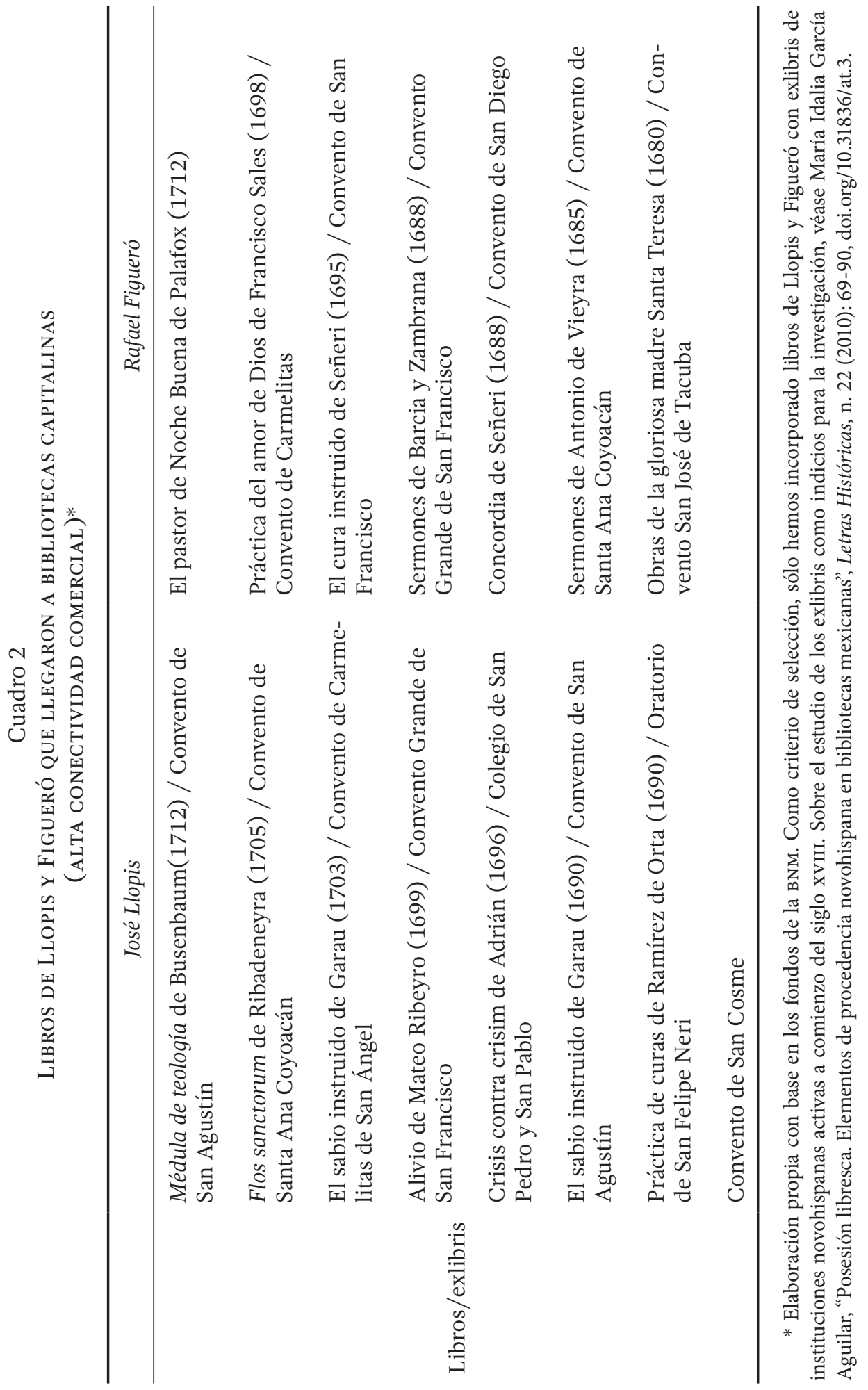


pano recomendarlos a un socio peninsular. Motivado por consideraciones de rentabilidad, Llopis entendió el potencial interés que podía suscitar entre el público de la península la obra del jesuita novohispano. Sin embargo, José Llopis falleció antes de poder llevar a cabo la reedición, la cual sus herederos pospusieron para más tarde. ${ }^{50}$ Mientras tanto, los ejemplares en su posesión pasaron entonces probablemente a otro impresor barcelonés cercano a Llopis: Juan Jolis. ${ }^{51}$ Los dos hombres habían pertenecido a la misma germandat dels estampers y ya habían trabajo juntos para la publicación de un libro en $1684 .{ }^{52}$ Sobre todo, Llopis había mantenido relaciones profesionales estrechas con el cuñado de Jolis: Rafael Figueró. ${ }^{53}$ Tal como Llopis, Jolis se convenció del potencial económico de la obra novohispana en el mercado peninsular. Durante el año de 1700, decidió pagar de su bolsillo una reedición integral. Sin ninguna concertación con el autor Martínez de la Parra o con sus correligionarios novohispanos, el catalán publicó una versión propia cuya dedicatoria suscribió él mismo y que vendió directamente en su local. ${ }^{54}$

A la venta en 1701, la reedición fue adaptada al mercado peninsular con nuevas licencias e imprimátur locales. ${ }^{55}$ Reuniendo en un solo volumen toda la doctrina de Martínez de la Parra, la versión de Jolis señaló la velocidad de circulación de las producciones intelectuales en los canales del comercio del libro de la Nueva España al corazón histórico del Imperio. A menos de dos años después de la reedición sevillana destinada al virreinato, el libro del poblano era introducido en el mercado peninsular en un formato adaptado a este. Descartados del proyecto editorial, los jesuitas se

${ }^{50}$ Falleció durante el año de 1699: Xevi Camprubí i Pla, "L’impressor Rafael Figueró (1642-1726) i la premsa a la Catalunya del seu temps", tesis de doctorado, Universidad de Barcelona, Facultad de Geografía e Historia, 2013), 57. Los herederos de Llopis emprendieron una reedición en 1704, la cual fue recuperada por Rafael Figueró, sobrino de Jolis: Camprubí i Pla, "L’impressor Rafael Figueró”, 445.

${ }^{51}$ Para explicar cómo le llegó la obra del poblano, Jolis señaló vagamente: "Quiso la fortuna que llegasse a mis manos [Luz de verdades católicas]", Martínez de la Parra, Luz de verdades, 1701, [f. 1v].

${ }^{52}$ Para un libro sobre la paz de Nimega.

${ }^{53}$ Llopis y Figueró colaboraron repetidas veces. Sobre Figueró, véase Ricard Expósito Amagat, "La prensa catalana en la guerra de Sucesión entre la información y el privilegio", en Géneros editoriales y relaciones de sucesos en la Edad Moderna, dir. de Pedro Cátedra (Salamanca: Universidad de Salamanca, 2013), 103-123.

${ }^{54}$ Según la portada: "vendese en su mesma casa".

${ }^{55} \mathrm{La}$ del ordinario es de 17 noviembre de 1700 y de las autoridades regias es del 16 de agosto de 1701. 
vieron despojados de ese modo en apenas algunos meses de la catequesis innovadora de uno de sus miembros por actores económicos con base en expectativas de ganancia.

La introducción temprana de una obra en España con base en una lógica de rentabilidad no constituía no obstante una garantía de éxito para el impresor Juan Jolis. En efecto, con Luz de verdades católicas, los circuitos barceloneses se limitaron a poner el libro en el mercado peninsular (vertiente de la oferta). De hecho, por entonces innúmeras obras se publicaban y aumentaban el catálogo de venta de los libreros sin suscitar particularmente el interés de los lectores. Las pláticas de Martínez de la Parra tenían además la característica de ser muy marcadas por su procedencia americana dentro de una oferta dominada por autores locales. Producida por un novohispano en la capital virreinal para su feligresía, abundaba en alusiones directas e indirectas a México, que constituía el punto de referencia de toda la obra. ${ }^{56}$ Este origen americano no implicaba no obstante nada significativo en el mercado peninsular, como lo demostraba el reciente éxito de sor Juana. Por una parte, el poblano pertenecía a una orden religiosa tanto conocida como respetada en España. Por otra, los reinos ibéricos y americanos del Imperio hispánico compartían una fuerte identidad colectiva. Tal como lo entendieron los impresores catalanes Llopis y Jolis, la obra de Martínez de la Parra se distinguía más que nada en el abanico de las nuevas publicaciones por su acercamiento innovador de una materia que estaba empezando también a suscitar preocupaciones en España.

En efecto, las necesidades de la catequesis estaban evolucionando también en la península con base en factores similares a los de la capital novohispana. ${ }^{57}$ No sólo se estaba afirmando una devoción más interiorizada sino también la nueva severidad devocional y sus propuestas austeras se estaban propagando en el corazón histórico del Imperio. ${ }^{58}$ Como en México, im-

56 Por ejemplo: "Por toda la República pregunto: está viva la República de México, o está muerta: Y respondo, que está como vosotros, padres, y como vosotras madres, la quereys”; "Como México, devia estar viciada la República de Athenas", ambas citas en Martínez de la Parra, Luz de verdades, 1701, 186.

${ }^{57}$ Según Resines: "El siglo XVIII es testigo de uno de los procesos de transformación de la catequesis llevado a cabo de la forma más insensible, pero más profunda”. Resines, $L a$ catequesis, 369. También Javier Burrieza Sánchez, "Un catecismo jesuítico en la España de la Ilustración. Pedro de Calatayud y la catequesis de la Compañía de Jesús”, Investigaciones Históricas: Época Moderna y Contemporánea, n. 19 (1999): 53-80.

58 Véase Antonio Mestre, "Sociedad y religión en el siglo XVIII", Chronica Nova, n. 19 (1991): 257-270. 
pulsaban a "hacer completa y extensiva una cultura religiosa que no quede reducida a las formas rudimentarias". ${ }^{59}$ Durante las primeras décadas del siglo XVIII, diferentes proposiciones surgirían en España para tratar de responder a estas nuevas expectativas que tendían a desechar las fórmulas vigentes de la catequesis. Por una parte, los catecismos clásicos de Ripalda y de Astete serían sometidos a procesos de actualización, con cambios e incluso expurgaciones puntuales decretadas por la Inquisición en $1736 .{ }^{60}$ Por otra, nuevas obras doctrinales, más complejas, verían la luz como los famosos Luz de la fe y de la ley del dominico zaragozano Jaime Barón y Arín o Cathecismo práctico del jesuita navarro Pedro de Calatayud. ${ }^{61}$

Tal como lo había conjeturado Jolis, su reedición de Luz de verdades católicas suscitó inmediatamente el interés de las autoridades eclesiásticas peninsulares en este contexto de transición. En primer lugar, la obra tenía la ventaja de inscribirse dentro de una gama catequística conocida y confiable para el clero, tanto por su trama como por su procedencia ignaciana. Del mismo modo que en la Nueva España, el catecismo de Ripalda constituía en la península un manual ineludible para la catequización de la feligresía, por lo cual sus citaciones recurrentes por parte del poblano remitían a una materia "no discutida por nadie". ${ }^{62}$ Asimismo, el uso del comentario o de narraciones breves formaba parte de los procedimientos corrientes de la enseñanza doctrinaria en el Imperio. ${ }^{63}$ Desde comienzo del siglo anterior, los doctrineros de la península llevaban además su ministerio casi exclusivamente con base en manuales ignacianos, como los cleros germánicos e italianos con las omnipresentes obras de Canisius y Belarmino. ${ }^{64}$ Se inclinaban pues fácilmente hacia producciones doctrinales jesuitas. En segundo

59 También: "llevar a cabo una presentación de la fe más y más completa, más y más minuciosa, de manera que no quede ningún asunto por abordar, ninguna cuestión en el tintero", Resines, La catequesis, 373.

${ }^{60}$ Burrieza Sánchez, "Un catecismo”; Resines, La catequesis, 395-399.

${ }^{61}$ También se podrían mencionar al castellano José Martín de la Sierra y su Mapa de arcanos y verdades o al extremeño José Ortiz Cantero y su Directorio cathechistico.

${ }^{62}$ Sobre el valor del catecismo de Ripalda: "Ha sido, por tanto, un refrendo de autoridad indiscutible para el catolicismo español”, Resines, La catequesis, 241.

${ }^{63}$ Resines, La catequesis, 336-337.

${ }^{64}$ Sobre la acción doctrinaria en España en el siglo XVIII, véase Antonio Viñao Frago, "Adoctrinadores y adoctrinados. Catequesis y educación en la España de la segunda mitad del siglo xVIII y primeros años del xix (I)", Cuadernos de Historia Moderna, n. III (2004): 85-111, doi.org/10.5209/CHMO. Sobre el papel central de los catecismos jesuitas en España: Burrieza Sánchez, "Un catecismo”. No fue el caso de otros espacios católicos como Francia, 
lugar, Luz de verdades católicas ofrecía un marco retórico inédito para la enseñanza doctrinal, que era capaz de responder, como lo había hecho en México, a las nuevas preocupaciones devocionales. Con su tono sensible y su lenguaje elegante, la doctrina del poblano proporcionaba un acceso renovado y más complejo al dogma. En ese sentido, el 12 de julio de 1701, el examinador sinodal del arzobispado barcelonés, Francisco Garrigo, comentó: "[Luz de verdades católicas] toca todo lo necessario de las Verdades católicas; y con estilo el más nuevo, y nunca visto, de Pláticas espirituales”. ${ }^{65}$

Con satisfacción para Juan Jolis, los primeros comentadores eclesiales de su reedición de Luz de verdades católicas destacaron entonces rápidamente su interés didáctico. Ya sea como manual para los curas o como libro de lectura para los fieles, preconizaron su incorporación al repertorio de los instrumentos doctrinales. Todavía en 1701, el eclesiástico catalán Francisco Garrigo indicó: "Con muy poco estudio, y diligencia, mediante este Libro, podrá cualquiera de ellos [los párrocos] adoctrinarlas [sus ovejas] en todo el discurso del año". ${ }^{66}$ Por su parte, el arzobispo barcelonés y sus pares obispos de Tarragona, Vique, Urgel, Girona y Solsona recomendaron directamente su lectura a sus feligreses. ${ }^{67}$ Para las autoridades clericales catalanas, el acercamiento innovador del poblano constituía, tal como en la Nueva España, una solución atractiva a unas necesidades doctrinales en proceso de renovación.

De hecho, el libro tuvo una muy buena acogida entre el público (vertiente de la demanda). Apenas cuatro años después, en 1705, el sobrino de Jolis, Rafael Figueró Jolis, imprimió 900 nuevos ejemplares de la versión de su tío, de los cuales 400 fueron destinados en exclusividad a sus clientes en el principado catalán. ${ }^{68}$ Sobre todo, en vista de su éxito, otros mercaderes de libros en la península se suscribieron a su vez a la obra del

donde el conflicto jansenista llevó a las autoridades diocesanas a redactar cada una su propio catecismo como medida de control.

${ }^{65}$ Martínez de la Parra, Luz de verdades, 1701, [f. 4r].

${ }^{66}$ Martínez de la Parra, Luz de verdades, 1701, [f. 4r]. También, según Garrigo: "Con que brilla como a Sol la caridad del Autor, pues quedándose para sí con la fatiga, y desvelos que le ha costado esta Obra, solo queda el descanso para los Párrocos, y Almas fiadas a su cuydado". Idem; "el fin que desea [LDVC], que es dar materiales, particularmente a los Párrocos, para que saquen de estas minas, riquezas inefables, con que llenen los entendimientos, y corazones de todos”. Martínez de la Parra, Luz de verdades, 1701, [f. 4r].

${ }^{67}$ Ofrecieron 40 días de indulgencia para la lectura de la obra tal como lo señala la portada.

${ }^{68}$ Camprubí i Pla, "L’impressor Rafael Figueró”, 99. 
jesuita novohispano. En 1705, mientras Figueró estaba alistando sus tirajes en Barcelona, el librero Francisco Laso financió en Madrid otra reedición de Luz de verdades católicas. Como sus pares catalanes, Laso era un hombre de negocios, impulsado por consideraciones económicas. Como ellos, su catálogo de venta se componía en parte de obras religiosas. Nuevamente sin concertarse con los jesuitas, el madrileño reprodujo la versión barcelonesa para venderla en su propia tienda. ${ }^{69}$ A pocos años de la introducción por Juan Jolis de Luz de verdades católicas en España, estas reediciones terminaron de ratificar la recuperación por los circuitos comerciantes peninsulares de la obra del poblano con base en una lógica de rentabilidad. Para los jesuitas novohispanos y para la Compañía en general, fue probablemente un motivo de descontento. En reacción, el representante jesuita en la Corte para las Indias, Alonso de Quirós, trataría en 1715 de recuperar los derechos legales sobre el libro, presentando una solicitud oficial de privilegio ante el Consejo de Castilla. ${ }^{70}$ Sin embargo, si bien Quirós la llegó a obtener, la difusión de la obra del poblano en España quedó mayoritariamente supeditada a la iniciativa de los sectores comerciantes peninsulares, dispuestos a satisfacer una demanda sostenida (véase el cuadro 3).

En efecto, tanto los sectores clericales como los fieles siguieron suscribiéndose a la doctrina de Martínez de la Parra. Después de las autoridades episcopales catalanas, Luz de verdades católicas sedujo al clero castellano por su acercamiento renovado de la doctrina. ${ }^{71}$ Por medio de Francisco Laso, los generales de la orden franciscana residentes en Madrid, Alonso de Biezma y José García, patrocinaron la obra en 1705 y $1717 .{ }^{72}$ A partir de la década de 1730, Luz de verdades católicas integró incluso el repertorio institucional de la literatura religiosa, avalada por la administración inquisitorial y regia (véase el cuadro 4). Por entonces, distintas proposiciones alternativas ya estaban empezando a difundirse, como la Luz de la fe y de la ley de Barón y Arín, o a surgir, como el Catecismo práctico y muy útil de Pedro de Calatayud. Como las pláticas del poblano, ambas obras aportaban a su vez respuestas novedosas y exitosas

${ }^{69}$ Según la portada: “A costa de Francisco Laso, Mercader de Libros: vendese en su casa”. [f. 3rv].

${ }^{70}$ Juan Martínez de la Parra, Luz de verdades católicas (Madrid: Francisco Laso, 1717),

${ }^{71}$ En 1722, el impresor Pedro del Castillo señaló: "en varias impressiones ha corrido con tan elevado crédito”, Juan Martínez de la Parra, Luz de verdades católicas (Madrid: Imp. Pedro del Castillo, 1722), [f. 1v].

${ }^{72}$ Martínez de la Parra, Luz de verdades católicas, Imp. Pedro del Castillo, 1722. 


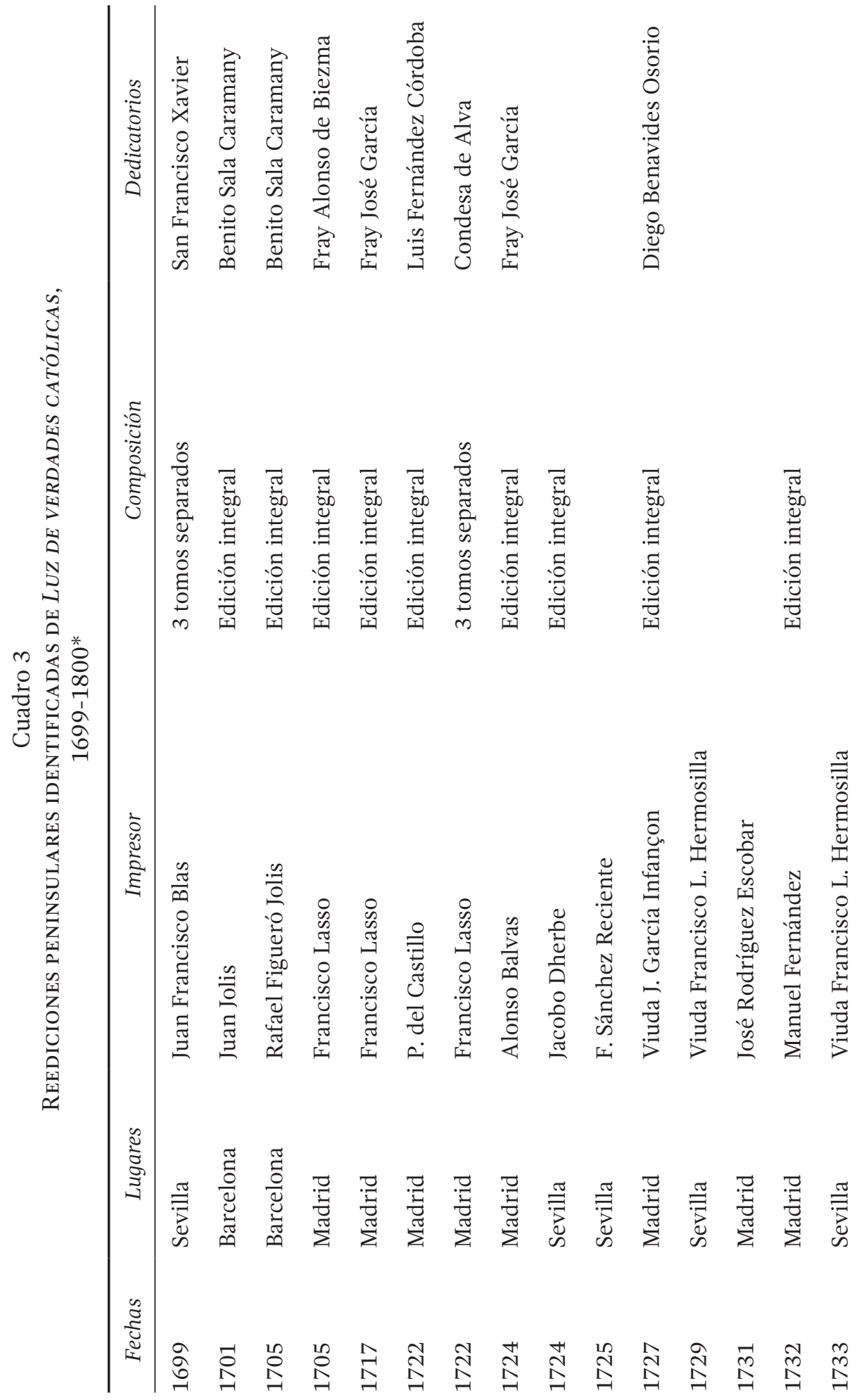




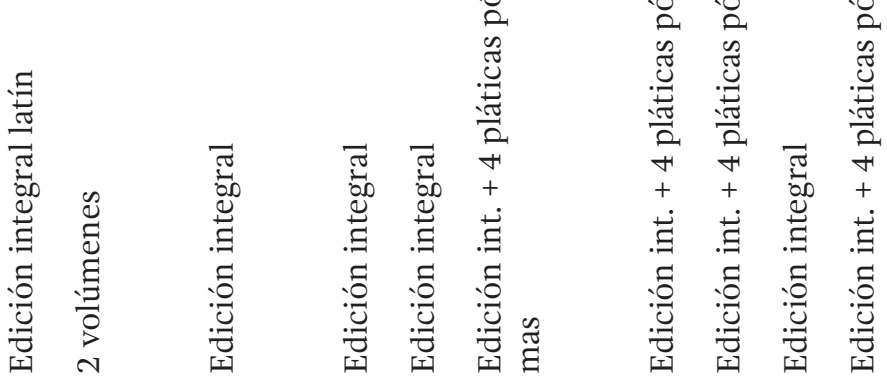

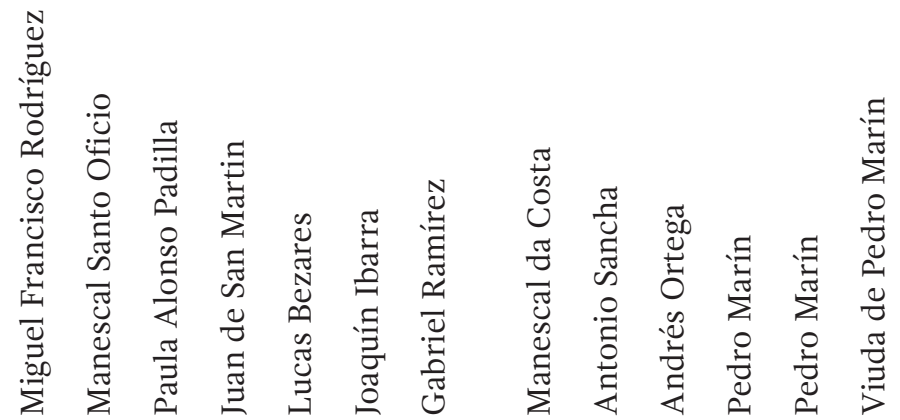

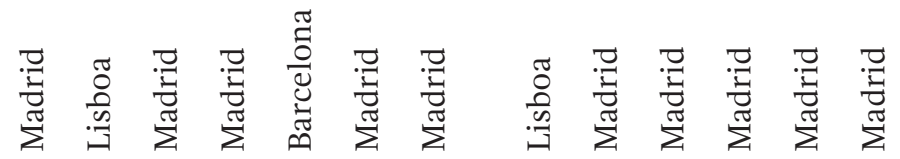

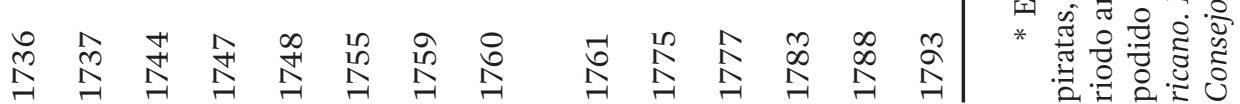




\section{Cuadro 4}

CARgos DE LOS IMPRESORES MADRILEÑOS DE LUZ DE VERDADES CATÓLICAS, 1731-1783 (ALTO GRADO DE OFICIALIDAD)*

\begin{tabular}{llc}
\hline \multicolumn{1}{c}{ Impresores } & \multicolumn{1}{c}{ Cargos } & \multicolumn{1}{c}{$\begin{array}{c}\text { Fechas } \\
\text { de impresión }\end{array}$} \\
\hline José Rodríguez Escobar & $\begin{array}{l}\text { Imprenta Real, consejo santa } \\
\text { cruzada, Real Academia }\end{array}$ & 1731 \\
Manuel Fernández & $\begin{array}{l}\text { Impresor cámara apostólica } \\
\text { (imp. de la Inquisición) }\end{array}$ & 1732 \\
Miguel Francisco Rodríguez & Imprenta Real & 1737 \\
Paula Alonso Padilla & hermana librero cámara del Rey & 1747 \\
Joaquín Ibarra & $\begin{array}{l}\text { Impresor de Cámara del rey, Real } \\
\text { Academia }\end{array}$ & 1759 \\
Gabriel Ramírez & $\begin{array}{l}\text { Imp. Real Academia de } \\
\text { San Fernando, criado de la Reyna }\end{array}$ & 1762 \\
Pedro Marín & $\begin{array}{l}\text { Imp. Secretaría de Marina, } \\
\text { Despacho Universal de Guerra }\end{array}$ & 1783 \\
Viuda Pedro Marín & $\begin{array}{l}\text { Imp. Real Compañía de } \\
\text { Impresores y Libreros }\end{array}$ & 1793 \\
\hline
\end{tabular}

* Elaboración propia.

a las inquietudes espirituales contemporáneas. La primera, del dominicano Barón y Arín, se estructuraba en torno a la trama de un náufrago en una isla. La segunda, del jesuita Calatayud, conservaba el principio básico de las preguntas y respuestas, pero añadía un fuerte componente moral al discurso. ${ }^{73}$ Pese a su interés, dichas obras no lograrían no obstante suplantar a Luz de verdades católicas, la cual se mantuvo durante todo el siglo XVIII como una respuesta sólida a las necesidades catequísticas en la península (véase el cuadro 5). ${ }^{74}$

73 "[T] oda mi solidez y cuidado es, desentrañar los vicios, afectos torcidos, y secretos del corazón, haciendo a los oientes anatomía de sus mismas consciencias, diciéndoles que les pasa en ellas, y poniendo a sus ojos sus mismos defectos, y desarmando las escusas con que se cubre el amor propio", Pedro de Calatayud, Catecismo practico y mui util para la instruccion y enseñanza facil de los fieles (Villagarcia: Imp. del Seminario, 1764), f. 5r.

${ }^{74}$ Sobre los catecismos publicados durante el siglo xvıII: José Menéndez y Joël Saugnieux, "Catequesis e ilustración. Aproximación a una encuesta bibliográfica", Archivum, n. LXXXIV (1984-1985): 119-142; Viñao Frago, “Adoctrinadores y adoctrinados”. 
Cuadro 5

COMPARACIÓN ENTRE REEDICIONES PARA EL SIGLO XVIII EN ESPAÑA DE CATECISMOS FAMOSOS (SUPERIORIDAD DE LDVC)*

\begin{tabular}{ccc}
\hline $\begin{array}{c}\text { Primera } \\
\text { edición }\end{array}$ & Título / Autor & $\begin{array}{c}\text { Número } \\
\text { de ediciones }\end{array}$ \\
\hline 1701 & Luz de verdades católicas / Juan Martínez de la Parra, s & 24 \\
1717 & Luz de la fe y de la ley / Jaime Barón y Arín, op & 18 \\
1747 & Catecismo práctico y muy útil / Pedro de Calatayud, sJ & 10 \\
\hline
\end{tabular}

* Elaboración propia con base en Palau y Dulcet, Manual. Para no deformar los resultados, no hemos integrado las cinco reediciones de Luz de verdades católicas que no señala Palau y Dulcet.

Esta recepción favorable del clero peninsular fue compartida por los feligreses. Si bien una parte de las reediciones sucesivas de Luz de verdades católicas sirvió a los doctrineros para sus actividades evangélicas, otra parte fue a parar en las manos de los fieles. De manera similar a la Nueva España, el lenguaje elegante del poblano y su complejización del catequismo tradicional ofrecía un acceso renovado al dogma para sus lectores en un contexto de renovación devocional. En este sentido, hacia enero de 1722, la duquesa de Alba se declaraba "enamorada de su hermosura". ${ }^{75}$ El mismo año, el impresor madrileño Pedro del Castillo señalaba al marqués de Montalbán que se trataba de "un libro tan propio para refinarse". ${ }^{76}$ En el transcurso el siglo, la doctrina de Martínez de la Parra invadió las bibliotecas privadas de la península para convertirse en uno de los libros más representados al lado de clásicos como la Imitación de Cristo de Kempis o la Introducción al símbolo de la fe de fray Luis de Granada. ${ }^{77}$ [f. 2v].

75 Juan Martínez de la Parra, Luz de verdades católicas (Madrid: Francisco Laso, 1722),

${ }^{76}$ Martínez de la Parra, Luz de verdades católicas, Pedro del Castillo, 1722 [f. 2v].

77 Teófanes Egido López, “Obras y obritas de devoción”, en Historia de la edición y de la lectura en España, 1475-1914, coord. de Víctor Infantes de Miguel, François Lopez y JeanFrançois Botrel (Madrid: Fundación Germán Sánchez Ruipérez, 2003), 416. 


\section{Conclusión}

En 1760, un correligionario de Juan Martínez de la Parra, el novohispano Francisco Xavier Lazcano, comentó con respecto al poblano: "se ha hecho amadíssimo en toda la dominación española, y aun en el Mundo Catholico, por las Pláticas de Doctrina Christiana, impressas ya repetidas veces". ${ }^{78}$ Dos años más tarde, en 1762, el dominico y bibliófilo francés Richard señalaba cuanto su obra "a eu grande vogue en Espagne". ${ }^{79}$ A sesenta años de su primera versión para el mercado peninsular, Luz de verdades católicas se había vuelto en efecto un clásico de la literatura doctrinaria en España. Resistiría luego incluso las purgas antijesuitas de Carlos III para alcanzar unas 45 reediciones a comienzo del siglo Xx. ${ }^{80}$ A finales del siglo XVII, la obra había nacido del contexto de la capital novohispana. Por circunstancias imprevistas, su autor se vio relegado de la alta predicación a la enseñanza doctrinaria. A partir de su excelencia oratoria, Martínez de la Parra propuso entonces una fórmula catequística inédita e innovadora. En un periodo de transformación de las prácticas religiosas en México, aquélla conoció un gran éxito entre los fieles capitalinos. Fue luego detectada por los sectores del libro en el Imperio, cuyo alto grado de conectividad permitió, anticipando su rentabilidad económica, su exportación rápida a España donde inquietudes doctrinales similares empezaban a manifestarse también. De manera similar a México, la obra del poblano aportó pues al público peninsular una solución entre otras al desafío de la renovación pedagógica de los instrumentos de la doctrina.

Este texto no tiene la pretensión de haberlo dicho todo sobre la exportación exitosa de Luz de verdades católicas fuera de las fronteras de la Nueva España. Diferentes elementos no han sido aludidos pese a su interés, como por ejemplo la difusión interamericana de la obra o fuera del Imperio. ${ }^{81} \mathrm{Sin}$

${ }^{78}$ Francisco Javier Lazcano, Vida exemplar y virtudes heroicas del venerable padre Juan Antonio de Oviedo (México: Imprenta del Real Colegio de San Ildefonso, 1760), 300.

${ }^{79}$ Charles-Louis Richard, Dictionnaire universel, dogmatique, canonique, historique, géographique (París: Imp. Rollin, Jombert, Bauche, 1762), v. v, 840.

${ }^{80}$ Charles E. O’Neill y Joaquín Domínguez, Diccionario histórico de la Compañía de Jesús: biográfico-temático (Madrid: Universidad Pontifica Comillas, 2001), v. III, 2525.

${ }^{81}$ Luz de verdades católicas se encontraba por ejemplo en bibliotecas tanto privadas como institucionales del virreinato de la Nueva Granada: José Rey Fajardo y Felipe González Mora, Los jesuitas en Antioquia: 1727-1767 (Bogotá: Pontificia Universidad Javeriana, 2008), 230, 232; Ildefonso Leal, Libros y bibliotecas en Venezuela colonial (Caracas: Academia Nacional de la Historia, 1978), v. II, 376. En 1713, se publicó una traducción al italiano, titulada Tromba catechistica, en la Nápoles de los Austrias. 
embargo, dos elementos de orden historiográfico pueden subrayarse. En primer lugar, la exportación y la adopción en el corazón histórico de la Monarquía de Luz de verdades católicas señala el policentrismo intelectual en el siglo XVIII. A diferencia de las circulaciones intelectuales de Europa hacia América, la obra del poblano ejemplifica no sólo la existencia de trayectorias contrarias sino su dimensión. Por un lado, la capital novohispana poseía por entonces las condiciones tanto humanas como técnicas de una centralidad erudita dentro del entramado imperial. En materia religiosa en particular, la ciudad constituía un polo intelectual particularmente activo e innovador, cuyo dinamismo era sostenido por un entorno tecnológico favorable, compuesto por redes de impresores, bibliotecas y establecimientos educativos (colegios y Universidad), que le permitió incluso anticiparse a los cambios devocionales que se estaban gestando en el Imperio a lo largo del siglo XVIII. Por otro lado, la capital virreinal tenía también una capacidad alta de exportación de sus producciones intelectuales gracias al grado elevado de conectividad de los circuitos del comercio del libro en el Imperio y a su posición dentro de dichos circuitos.

En segundo lugar, el éxito en el corazón histórico de la Monarquía de la obra del jesuita novohispano muestra el interés para la investigación en detectar y estudiar las otras trayectorias contemporáneas similares. Ya sea en teología moral o en teología mística, las obras de dos contemporáneos inmediatos de Martínez de la Parra en la Nueva España, el dominico Francisco Sánchez y el jesuita Manuel Godínez, conocieron por ejemplo también repercusiones importantes del otro lado del Atlántico con base en la pertinencia de sus proposiciones intelectuales. En 1680, Sánchez publicó en Madrid un libro que promovía un antiprobabilismo inédito. Si bien su publicación le costó una dura polémica con los franciscanos castellanos, le valió la condición de precursor del rigorismo en toda su orden..$^{82} \mathrm{El}$ año siguiente, 1681, Godínez dio a luz en Puebla a su Práctica de la theología mystica. Apenas unos meses después, la obra tuvo una primera versión sevillana para luego conocer, como en el caso de Martínez de la Parra, diversas reediciones y difundirse entre los fieles en España. ${ }^{83}$ En ese sentido, muchos de ellos fueron sin duda instruidos o guiados por obras americanas.

${ }^{82}$ Para la polémica, véase Francisco Díaz de San Buenaventura, Primera parte del Espejo serafico, destierro de ignorancias (Santiago de Compostela: Antonio Frayz, 1683). Su proceder fue saludado en 1743 por el dominico italiano Daniello Concina en su libro Storia del probabilismo e rigorismo.

${ }^{83}$ Palau y Dulcet identifica siete reediciones de la obra en España hasta 1789. Tuvo incluso una traducción al italiano en Venezia en 1748 y al latín en 1740 en Roma. 


\section{BiBLIOGRAFÍA}

Burrieza Sánchez, Javier. "Un catecismo jesuítico en la España de la Ilustración: Pedro de Calatayud y la catequesis de la Compañía de Jesús", Investigaciones Históricas. Época Moderna y Contemporánea, n. 19 (1999): 53-80.

Calatayud Pedro. Catecismo practico y mui util para la instruccion y enseñanza facil de los fieles. Villagarcía: Imp. del Seminario, 1764.

Camprubí i Pla, Xevi. "L’impressor Rafael Figueró (1642-1726) i la premsa a la Catalunya del seu temps." Tesis de doctorado. Universidad de Barcelona, Facultad de Geografía e Historia, 2013.

Cardim, Pedro, Tamar Herzog, José Javier Ruiz Ibáñez y Gaetano Sabatini, eds. Polycentric monarchies. How did Early Modern Spain and Portugal Achieve and Maintain a Global Hegemony? Sussex: Academic Press, 2014.

Chinchilla Pawling, Perla. De la "compositio loci" a la república de las letras. Predicación jesuita en el siglo XVII novohispano. México: Universidad Iberoamericana, 2004.

Corcuera, Sonia. Del amor al temor. Borrachez, catequesis y control en la Nueva España (1555-1771). México: Fondo de Cultura Económica, 1994.

Cordero, Macarena. "Reproducción y traducción de la cultura judicial hispana en el imaginario indígena." Estudios de Historia Novohispana, n. 57 (2017): $8-26$.

Díaz de San Buenaventura, Francisco. Primera parte del Espejo Seráfico, destierro de ignorancias, y antorcha contra las últimas dudas. Santiago de Compostela: Imp. Antonio Frays, 1683.

Egido López, Teófanes. "Obras y obritas de devoción." Historia de la edición y de la lectura en España, 1475-1914. Coordinación de Víctor Infantes de Miguel, François Lopez y Jean-François Botrel, 415-423. Madrid: Fundación Germán Sánchez Ruipérez, 2003.

Expósito Amagat, Ricard, "La prensa catalana en la guerra de Sucesión entre la información y el privilegio." En Géneros editoriales y relaciones de sucesos en la Edad Moderna. Dirección de Pedro Manuel Cátedra García y edición literaria de María Eugenia Díaz Tena. Salamanca: Universidad de Salamanca, 2013.

Florencia, Francisco. Exemplar vida y gloriosa muerte por Christo del fervoroso P. Luis de Medina de la compãnia de Jesus. Sevilla: Imp. Juan Francisco de Blas, 1673.

Galicia Lechuga, David, y Jorge Gutiérrez Reyna. "Un impresor seducido por sor Juana: los textos de las sueltas novohispanas publicados por José Llopis en poemas (1691)." Calíope: Journal of the Society for Renaissance and Baroque Hispanic Poetry, v. 23, n. 2 (2018): 217-233. 
García Aguilar, María Idalia. "Posesión libresca. Elementos de procedencia novohispana en bibliotecas mexicanas.” Letras Históricas, v. 22, n. 3 (2010): 69-90. García-Ahumada, Enrique. "La inculturación en la catequesis inicial de América." Anuario de Historia de la Iglesia, n. 3, (1994): 215-232.

Godínez, Miguel. Práctica de la theologia mystica. Sevilla: Imp. Juan Vejarano, 1682 .

Gómez, Cristina. Navegar con libros. El comercio de libros entre España y Nueva España. Madrid: Trama Editorial, 2011.

Gonzalvo, Pilar. Historia de la educación en la época colonial. La educación de los criollos. México: Fondo de Cultura Económica, 1990.

Guerra, François-Xavier. Modernidad e independencias. Ensayos sobre las revoluciones hispánicas. Madrid: MAPFRE, 1992.

Gutiérrez Casilla, José. Diccionario bio-bibliográfico de la Compañía de Jesús en México. México: Jus, 1961.

Gutiérrez Reyna, Jorge. "El texto del Primero sueño. Transmisión, editores, retos de la edición crítica." (An)ecdótica, v. 3, n. 2 (2019): 71-92.

Herrero Salgado, Félix. La oratoria sagrada en los siglos XVI y XVII. Madrid: Fundación Universitaria Española, 1998.

Justiniano, María Fernanda. "América: de colonia a reino y de periferia a centro." Nuevo Mundo, Mundos Nuevos [en línea], Debates, 2016.

Lampérière, Annick, coord. L'Amérique Latine et les modèles européens. París: L'Harmattan, 1998.

Lara González, Beatriz. La Real Compañía de Impresores y Libreros de Madrid: siglo XVIII y siglo XIX. Madrid: Universidad Complutense, 2015.

Laske, Trilce. “Un eclesiástico con dimensión imperial en México: Juan Martínez de la Parra y la consagración intelectual (1680-1701).” Historias, Instituto Nacional de Antropología e Historia, n. 99 (2018): 33-50.

Lazcano, Francisco Javier. Vida exemplar y virtudes heroicas del venerable padre Juan Antonio de Oviedo. México: Imprenta del Real Colegio de San Ildefonso, 1760.

Luque Alcaide, Elisa. "Debates doctrinales en el IV Concilio Provincial Mexicano (1771).” Historia Mexicana, v. LV, n. 217 (2005): 5-66.

Leal, Ildefonso. Libros y bibliotecas en Venezuela colonial. Caracas: Academia Nacional de la Historia, 1978.

Lezamis José. Breve relación de la vida, y muerte del Ill. y Rmo. Señor Doctor D. F. de Aguiar, y Seyjas. México: Imp. Benavides, 1699.

Martínez de la Parra, Juan. La nada y todas las cosas, unidas en la santidad admirable de [...] S Francisco de Assis. México: Imp. Benavides, 1698.

Martínez de la Parra, Juan. Memoria agradecida a la dedicación del sumptuoso retablo. México: Imp. Benavides, 1698. 
Martínez de la Parra, Juan. Luz de verdades católicas y explicación de la doctrina cristiana. Barcelona: Imp. Juan Jolis, 1701A.

Martínez de la Parra, Juan. Luz de verdades católicas y explicación de la doctrina cristiana. Sevilla: Imp. J. Fco. Blas, 1699B, v. II-III.

Martínez de la Parra, Juan. Luz de verdades católicas y explicación de la doctrina cristiana. Barcelona: Imp. Rafael Figueró, 1705.

Martínez de la Parra, Juan. Luz de verdades católicas y explicación de la doctrina cristiana. Madrid: Francisco Laso, 1705.

Martínez de la Parra, Juan. Luz de verdades católicas y explicación de la doctrina cristiana. Madrid: Francisco Laso, 1717C.

Martínez de la Parra, Juan. Luz de verdades católicas y explicación de la doctrina cristiana. Madrid: Imp. Pedro del Castillo, 1722D.

Martínez de la Parra, Juan. Luz de verdades católicas y explicación de la doctrina cristiana. Madrid: Francisco Laso, 1722E.

Martínez López-Cano, María del Pilar. Concilios provinciales mexicanos. México: Universidad Nacional Autónoma de México, 2004.

Mayer, Alicia. Lutero en el paraíso. La Nueva España en el espejo del reformador alemán. México: Fondo de Cultura Económica, 2008.

Mayer, Alicia. La Reforma católica en Nueva España. Confesión, disciplina, valores sociales y religiosidad en el México virreinal. Una perspectiva de investigación. México: Universidad Nacional Autónoma de México, 2010.

Medina, José Toribio. La imprenta en la Puebla de los Ángeles. Santiago de Chile: Imp. Cervantes, 1908.

Menéndez, Jesús, y Joël Saugnieux. "Catequesis e Ilustración: Aproximación a una encuesta bibliográfica." Archivum, xxxIV (1984-1985): 119-142.

Mestre, Antonio. "Sociedad y religión en el siglo XviII." Chronica Nova: Revista de historia moderna de la Universidad de Granada, n. 19 (1991): 257-270.

Morán Reyes, Ariel Antonio. "No hay término ni fin en hacer ni multiplicar los libros. Las casas de impresores y la diversificación de la cultura libresca durante el siglo XVII en la capital novohispana." Revista Complutense de Historia de América, n. 45 (2019): 159-187.

Meregalli, Franco. La literatura desde el punto de vista del receptor. Amsterdam: Rodopi, 1989.

O’Neill, Charles E., y Joaquín Domínguez. Diccionario histórico de la Compañía de Jesús: biográfico-temático. Madrid: Universidad Pontifica Comillas, 2001.

Palau y Dulcet, Antonio. Manual del librero hispano-americano. Inventario bibliográfico de la producción científica y literaria de España y de la América Latina. Barcelona: Librería Antiquaria, 1926. 
Pérez, Manuel. Los cuentos del predicador: historias y ficciones para la reforma de costumbres en la Nueva España. Madrid: Iberoamericana, 2011.

Resines, Luis. La catequesis en España. Historia y textos. Madrid: Biblioteca de Autores Cristianos, 1997.

Rey Fajardo, José, y Felipe González Mora. Los jesuitas en Antioquia: 1727-1767. Bogotá: Pontificia Universidad Javeriana, 2008.

Richard, Charles-Louis. Dictionnaire universel, dogmatique, canonique, historique, géographique. París: Imp. Rollin, Jombert, Bauche, 1762.

Rodríguez Moya, Inmaculada, ed. Iberoamérica en perspectiva artística transferencias culturales y devocionales. Castelló: Universitat Jaume I, 2016.

Robles, Antonio. Diario de sucesos notables. México: Porrúa, 1972.

Rodriguez, Matias. Explicación de las sesenta y cinco proposiciones prohibidas por la santidad de N. M. S. P. Innocencio XI. Puebla: Imp. Fernández de León, 1684.

Rubial García, Antonio. "Un nuevo laico ¿un nuevo Dios? El nacimiento de una moral y un devocionalismo 'burgueses' en Nueva España entre finales del siglo XVII y principios del XVIII.” Estudios de Historia Novohispana, n. 56 (2017): $1-25$.

Sánchez, Francisco. Examen de las indulgencias que legitimamente gozan las Religiones, y Cofradias, según las más modernas decisiones y decretos de los Romanos Pontífices. Madrid: Imp. Garcia Infançon, 1680.

Velasco, Tomás. Breviloquio moral practico, en que se contienen las sesenta y cinco proposiciones prohibidas por N. SS. P. Innocencio XI, declaradas por via de impugnación. México: Imp. Viuda Bernardo Calderón, 1681.

Viñao Frago, Antonio. "Adoctrinadores y adoctrinados. Catequesis y educación en la España de la segunda mitad del siglo XVIII y primeros años del XIX (I)." Cuadernos de Historia Moderna. Anejos, III (2004): 85-111.

\section{SOBRE LA AUTORA}

Posdoctorante del Instituto de Investigaciones Históricas de la UNAM, bajo la asesoría del doctor Iván Escamilla. Trabaja temas de Historia intelectual para el periodo virreinal. En particular, se ha dedicado a las últimas décadas del siglo XVII y al auge del rigorismo en la Nueva España. Sobre el tema, ha publicado el artículo: "Jansenismo y rigorismo en la Nueva España: una propuesta de renovación historiográfica (1660-1700)”, Historia Mexicana, El Colegio de México, n. 282, 2021 [en prensa]. 